\title{
Morphological Observations on the Shell of Fresh Water Turtles and Tortoises Found in Sri Lanka
}

\author{
Nadeesha Dilrukshi HN1, Anura P Jayasooriya ${ }^{2,3}$ and Gamika A Prathapasinghe ${ }^{1 *}$ \\ ${ }^{*}$ Department of Livestock and Avian Sciences, Faculty of Livestock, Fisheries and Nutrition, Wayamba University of Sri Lanka \\ 2Department of Basic Veterinary Sciences, School of Veterinary Medicine, Faculty of Medical Sciences, University of the West Indies, Trinidad and \\ Tobago, West Indies \\ ${ }^{3}$ Department of Basic Veterinary Sciences, Faculty of Veterinary Medicine Animal Science, University of Peradeniya, Peradeniya, Sri Lanka
}

*Corresponding author: Gamika A. Prathapasinghe, Department of Livestock and Avian Sciences, Faculty of Livestock, Fisheries and Nutrition, Wayamba University of Sri Lanka, Makandura, Gonawila, 60170, Sri Lanka; Tel: +94773457233; Email: gamika@gmail.com

Received: May 23, 2019; Accepted: June 07, 2019; Published: June 14, 2019

\begin{abstract}
Sri Lankan freshwater turtles; Melanochelys trijuga parkeri, Melanochelys trijuga thermalis, Lisseymys puntata punctata and land tortoise; Geochelone elegans face a significant threat of population reduction due to various environmental and man-caused factors. Management and conservation of these threatened species have been hindered by the scarcity of necessary scientific information. Thus, our scientific observations on these species are documented to provide morphological information for future use in research, management and conservation aspects. A total of 56 healthy adult tortoises, Melanochelys trijuga parkeri $(\mathrm{n}=05)$, Melanochelys trijuga thermalis $(\mathrm{n}=25)$, Lissemys punctata punctata $(\mathrm{n}=12)$ and Geochelone elegans $(\mathrm{n}=14)$ were selected for the study. They were raised in tortoise holding facility which was set-up with an environment that resembled to their natural habitat. Shell morphometrics were observed and measured using a flexible tape ruler. Weight was recorded for using a top loading balance. Morphological observations of Melanochelys trijuga thermalis and Melanochelys trijuga parkeri were common scutation in its carapace and plastron. Carapacial scutation was with single nuchal, five vertibrals, four pairs of costals and twelve pairs of marginals. Geochelone elegans had the same pattern but in carapace no nuchal was observed, but there was a supracaudal. Plastron of Melanochelys trijuga thermalis, Melanochelys trijuga parkeri and Geochelone elegans had the same pattern in gular, humeral, pectoral, abdominal, femoral and anal were paired. Lissemys punctata punctata had soft fleshy carapace and plastron. In conclusion, it was evident low availability of Melanochelys trijuga parkeri when compare to the other testudines and increased body weight was associated with increased carapace length, carapace width, carapace height, plastron length, and plastron width of these testudines.
\end{abstract}

Keywords: fresh water Turtles, tortoise, Shell, morphology, body weight

\section{Introduction}

Sri Lanka is an island country, in the Indian Ocean southwest of the Bay of Bengal south Asia with many agro-ecological subregions in wet, intermediate and dry climatic zones. The rich biodiversity in aquatic and terrestrial habitats is based on the heterogeneity of climatic, topographic and soil conditions in Sri Lanka [1]. Natural ecosystems and habitats composed of Forests and grasslands, freshwater and marine wetlands, rivers, streams, mangroves, and coral reefs in Sri Lanka. Further, Conservation International (CI) has identified Sri Lanka together with the Western Ghats of India as one of the 34 global biodiversities "hotspots" with a high concentration of endemic species [2]. Amphibians and reptiles play a vital role in maintaining and regulating ecosystem functions; nutrient cycling, bioturbation, pollination, seed disposal, energy flow as predator or prey [3]. Interestingly, marine turtles, land tortoises and freshwater terrapins representing the all three major clades of chelonians (Class: Reptilia, Order: Testudines) can be found in Sri Lanka [4]. Natural ecosystems and habitats provide habitats for Testudines' family includes five (05) marine turtle species and four (04) freshwater turtle species including; Black Turtle (Melanochelys trijuga thermalis),
Parker's Black Turtle (Melanochelys trijuga parkeri), Flap-Shell Turtle (Lissemys puntata punctata) and Red-eared slider (Trachemys scripta), a well-known introduced alien invasive species (Das \& De Silva, 2005). These terrapins can be found in a variety of aquatic and semiaquatic habitats including wetlands, running water, stagnant water throughout the country and they feed on a wide range of food including aquatic and semi-aquatic plants, fruits, many invertebrates and animal feces [5]. These terrapin populations are suffering from severe threats due to the exploitation of natural habitat, human consumption, pet trade, depletion of prey species and ingestion of synthetic materials [6]. According to the 1999 list of threatened species of Sri Lanka published by IUCN, Melanochelys trijuga thermalis, Lissemys punctata punctata and Geochelone elegans species are considered to be nationally threatened and Melanochelys trijuga parkeri categorized as an endemic species which is listed under IUCN 2002 global red list.

A global action plan for the conservation of freshwater turtles and tortoises was implemented with different initiations ex: captive breeding and management programs, promote research activities, trade monitoring, sustainable harvest programs throughout the world 
[7]. Unfortunately, Conservation of Sri Lankan freshwater turtles faced many challenges due to lack of existing herpetological literature. In spite of that, there are many chelonian research and conservation efforts are carried out with towards marine turtles in Sri Lanka [8].

Given this situation, the management and conservation of freshwater turtles and tortoises in Sri Lanka must be backed by active research programs since very few studies have directed their attention related to these subjects [4]. Moreover, it is essential to generate to basic information related to population dynamics, especially concerning structure (age, sex, size, and weight of individuals), population density, and use of habitat and related to their biological aspects, etc.

The main objective of this article is to contribute scientific information related to shell characteristics of Sri Lankan freshwater turtles and tortoise in captive conditions.

\section{Methodology}

\section{Ethical statement}

The research work was conducted according the guidance stipulated by Animal Ethics Committee of Wayamba University of Sri Lanka (Application No: 201509AI04, approval was granted on 22 September 2015). Though all these animal species were kept under captivity, they were provided with a suitable natural environment to minimize the stress that may cause due to the captive nature.

\section{Study population}

A total of 56 male and female tortoises from four different types, Geochelone elegans $(\mathrm{n}=14)$, Melanochelys trijuga parkeri $(\mathrm{n}=05)$, Melanochelys trijuga thermalis $(\mathrm{n}=25)$ and Lissemys punctata punctate $(n=12)$ were recruited as subjects. They were kept at the Tortoise holding facility, Department of Livestock and Avian Sciences, Wayamba University of Sri Lanka.

\section{Morphological observations}

Records were made on pigmentation differences on the carapace and plastron, differences in between male and females and morphological variations within the populations. Weight of an individual was measured using a top loading balance.

\section{Morphometrics of Shell}

Total Carapace Length (TCL), Total Carapace Width (TCW), Total Plastron Length (TPL), Total Plastron Width (TPW) and Height were obtained using vernier caliper (resolution $1.00 \mathrm{~mm}$ and $0.1 \mathrm{~mm}$, respectively) and a flexible tape ruler (resolution $1.00 \mathrm{~mm}$ ) for straight and curved measurements, respectively.

\section{Results and Discussion}

According to the morphological observations of Melanochelys trijuga parkeri and Melanochelys trijuga thermalis have common scutation on their carapace and plastron.

The shell of Melanochelys trijuga parkeri and Melanochelys trijuga thermalis consist of an upper carapace and lower plastron connected laterally by bony bridges. The carapace scutes are in black or dark coppery red with or without a yellow margin to the plastron. The plastron is dark brown or black and usually possesses a diffuse, dirty yellow lateral margin.

Melanochelys trijuga thermalis has yellow to orange color spots on the dorsal surface of head skin, Melanochelys trijuga parkeri doesn't have such color pattern and which is uniformly olive brown color. The neck is moderate and possesses three or four lateral longitudinal folds.

Limbs are strongly scaled with movable digits which are webbed and with grey or white skin near to carapace.

This terrapins are subject to considerable individual variation in colour on their carapace and plastron. It is very important to study pigmentation changes on the carapace and plastron throughout the growth period because we have observed more colour variations in young ones when compared to the adults.

The male possesses a concave plastron with more reflex angled ( $\mathrm{B}>\mathrm{A})$ in comparison to the female. The female's tail is much shorter in length than males $(\mathrm{C}<\mathrm{D})$. Male has $\mathrm{V}$ shaped anal scutes whereas in females it is $\mathrm{U}$ shaped. Plastron is concave in males and female plastron is flat.

It is interesting to note that of all Melanochelys trijuga parkeri were males. We were unable to find females from Melanochelys trijuga parkeri during our study period.

Morphologically, Melanochelys trijuga thermalis are differentiated from Melanochelys trijuga parkeri by using yellow to orange color spots on their head and neck area.

Geochelone elegans is easily recognized by the black and yellow stellate pattern upon its carapace and using pointed uneven scales. It is more strongly domed with pointed uneven vertibrals. Plastron is somewhat shorter than the carapace.

The head is moderate in size and covered with a few enlarged, and numerous small scales. Fore and hind limbs consist of claws and they are having pointed flat scales directed towards claws.

In adult male the tail is more elongated than that of the female, the supracaudal scute ends well below the level of the other marginal and is wider than the last vertebral and curves strongly inwards. The plastron is concave. In the adult female the supracaudal scute ends at the same level as the other marginals and is narrower than the last vertebral and slants straight downwards (Figures 1 - 14). Male animals were smaller than females.

Lissemys punctata punctata has soft fleshy carapace and plastron. This species can completely retracte its limbs when the plastral flaps are pulled tightly against the bony rim of the carapace. This ability can act as additional protection for the hind limbs.

This soft terrapin is easily distinguished from other local testudines by its scuteless smooth skinned carapace, tubate nostrils, fleshy lips (c) and three clawed limbs with a few vestigial scales (d). The secondary sexual characters were poorly observed with our experimental group of Lissemys punctata punctate. 


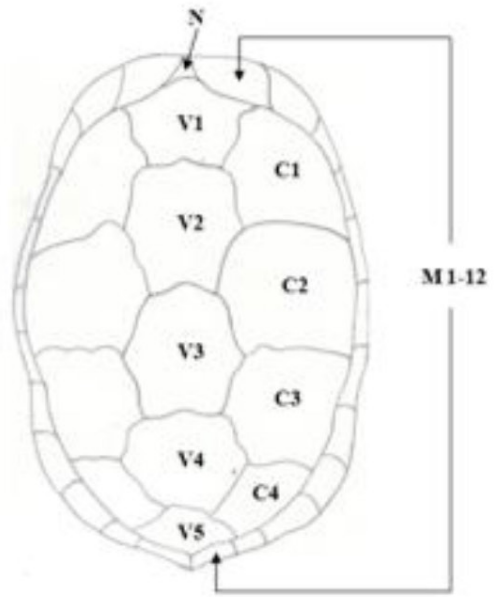

Carapace

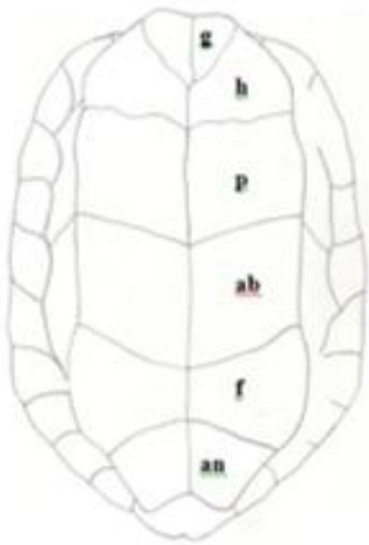

Plastron

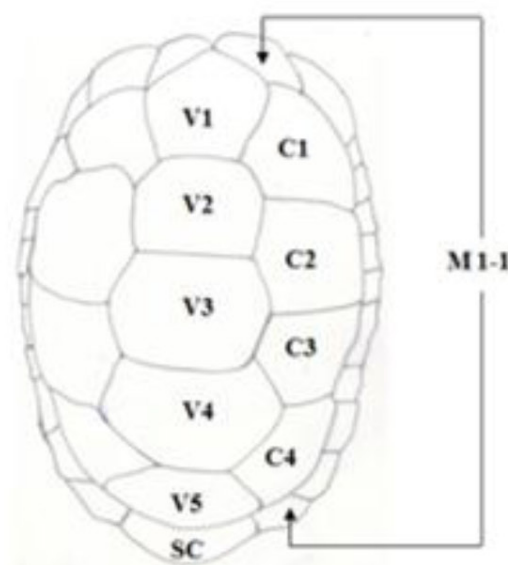

Carapace

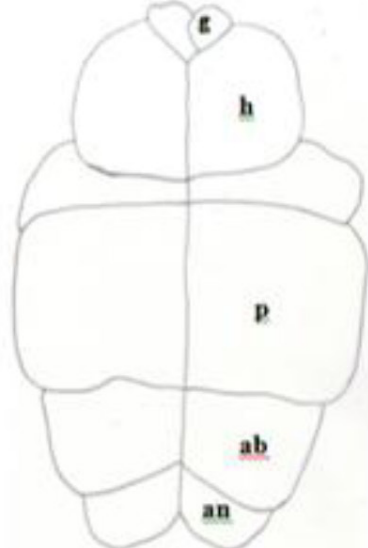

Plastron

A

B

Figure 1. Pattern of scutes on carapace and plastron of Melanochelys trijuga parkeri and Melanochelys trijuga thermalis: Carapace, (N) Nucal (1), (V) Vertibrals (1-5), (C) Costals (1-4, both sides), (M) Marginal (1-12, both sides): Plastron, (g) gular, (h) humeral, (p) pectoral, (ab) abdominal, (f) femoral and (an) anal (all paired) and B. Geochelone elegans: Carapace, (V) Vertibrals (1-5), (C) Costals (1-4, both sides), (M) Marginal (1-12, both sides) and (SC) Supracaudal : Plastron (g) gular, (h) humeral, (p) pectoral, (ab) abdominal, (f) femoral and (an) anal (all paired)
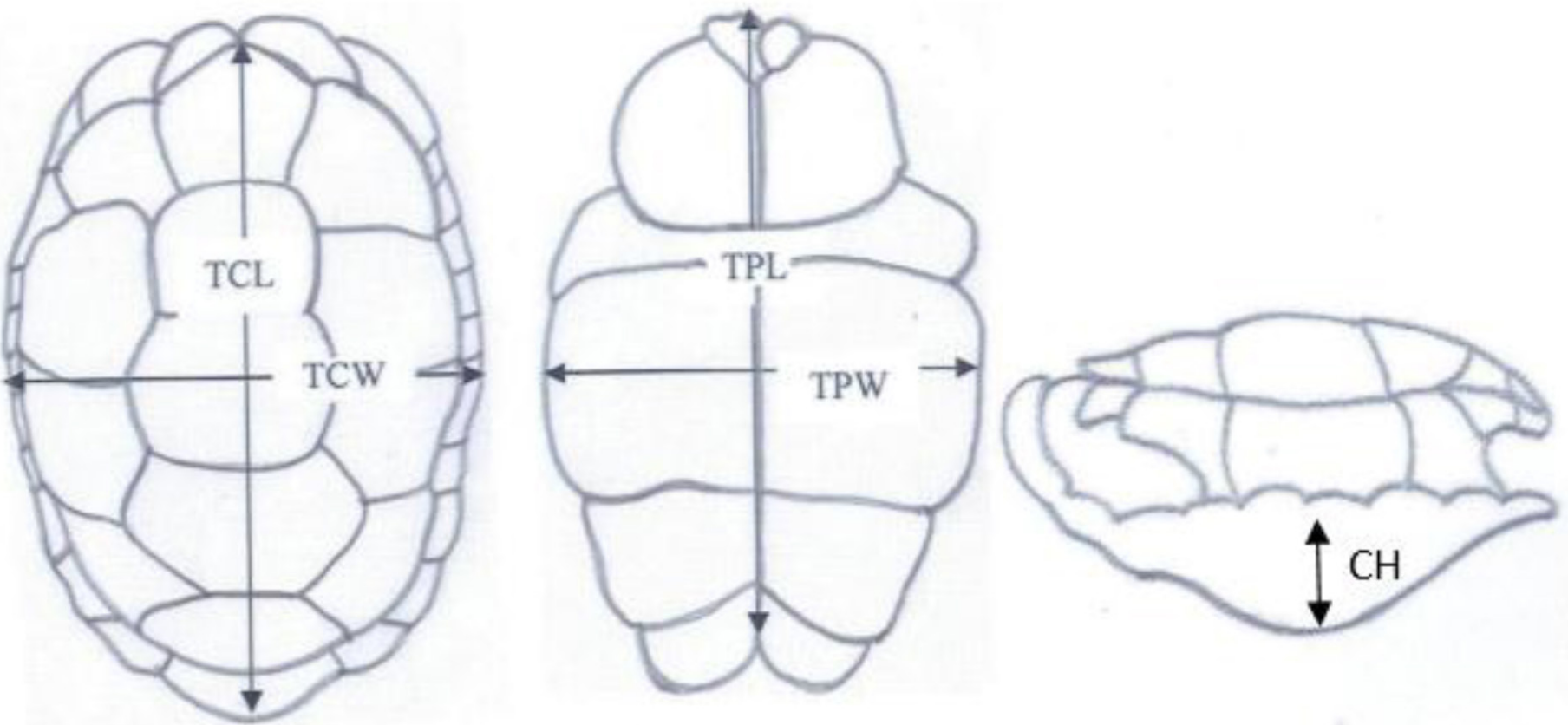

Figure 2. Shell Measurements 

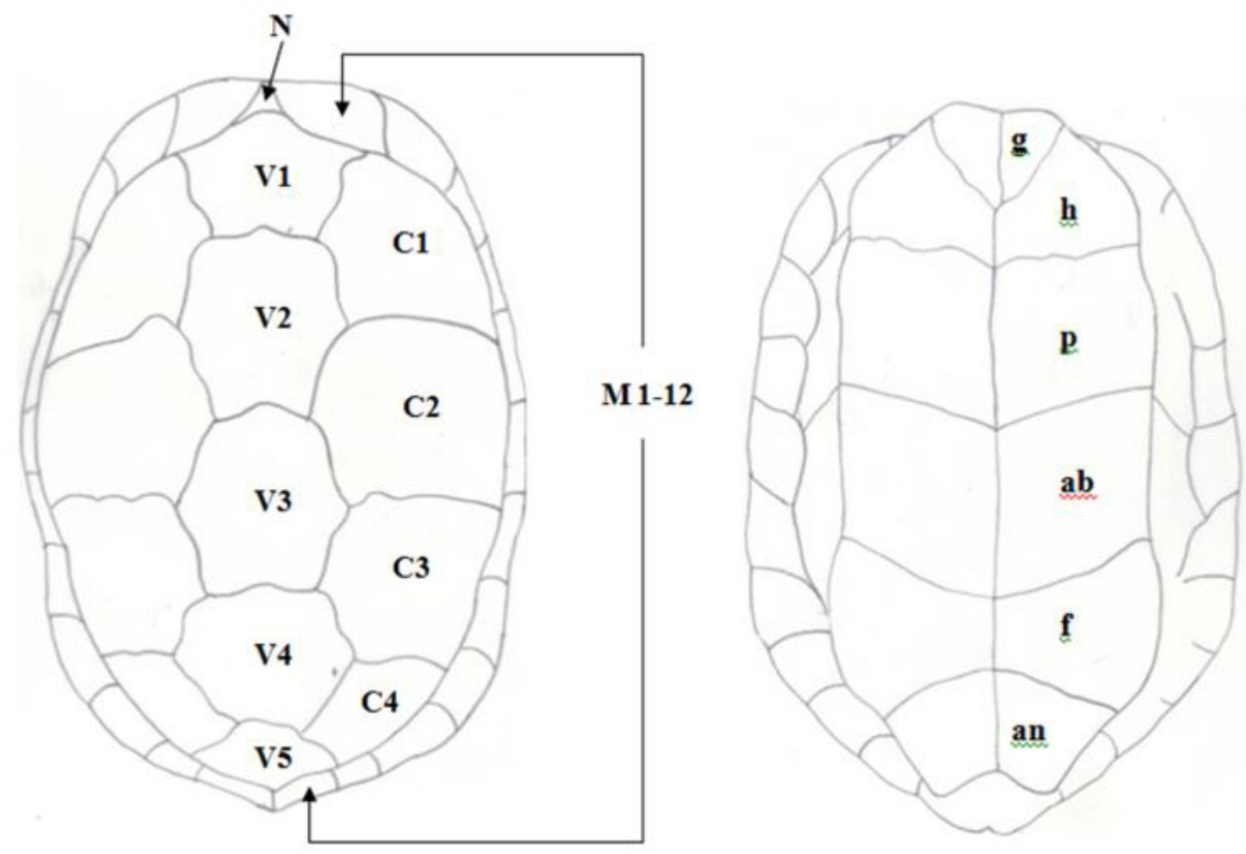

Figure 3. Pattern of scutes on carapace and plastron of Melanochelys trijuga parkeri and Melanochelys trijuga thermalis : Carapace, (N) Nucal (1), (V) Vertibrals (1-5), (C) Costals (1-4, both sides), (M) Marginal (1-12, both sides): Plastron, (g) gular, (h) humeral, (p) pectoral, (ab) abdominal, (f) femoral and (an) anal (all paired)

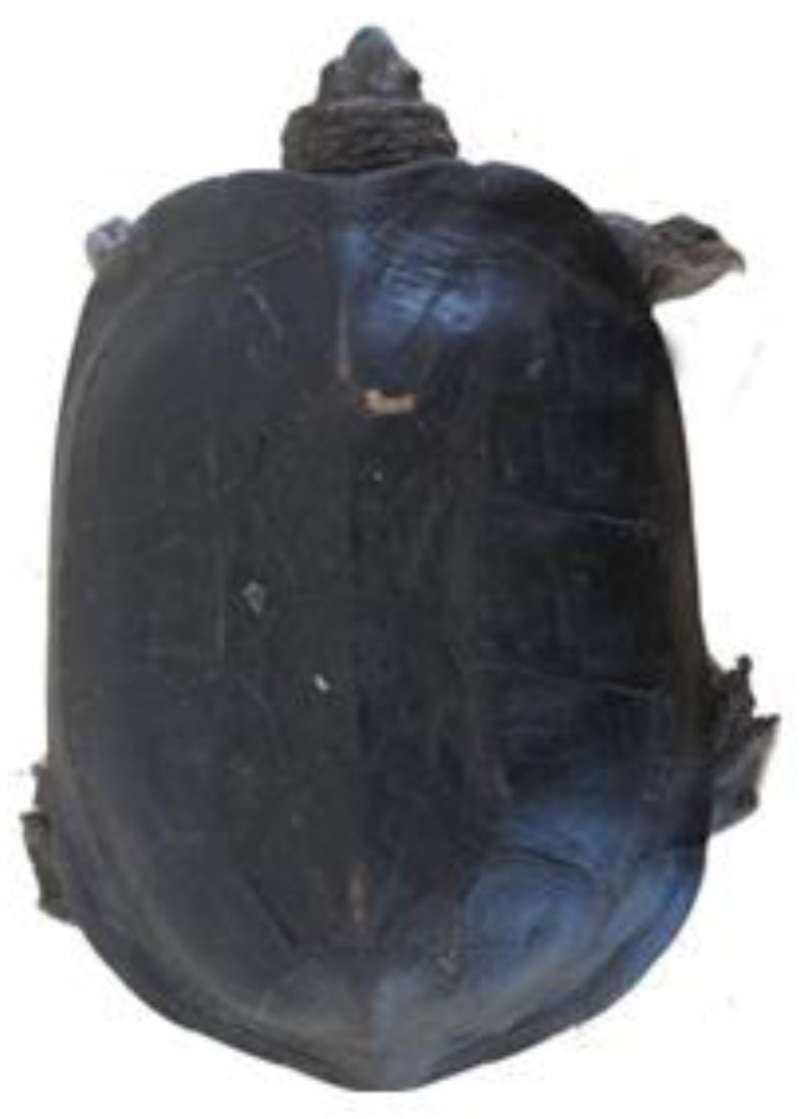

A

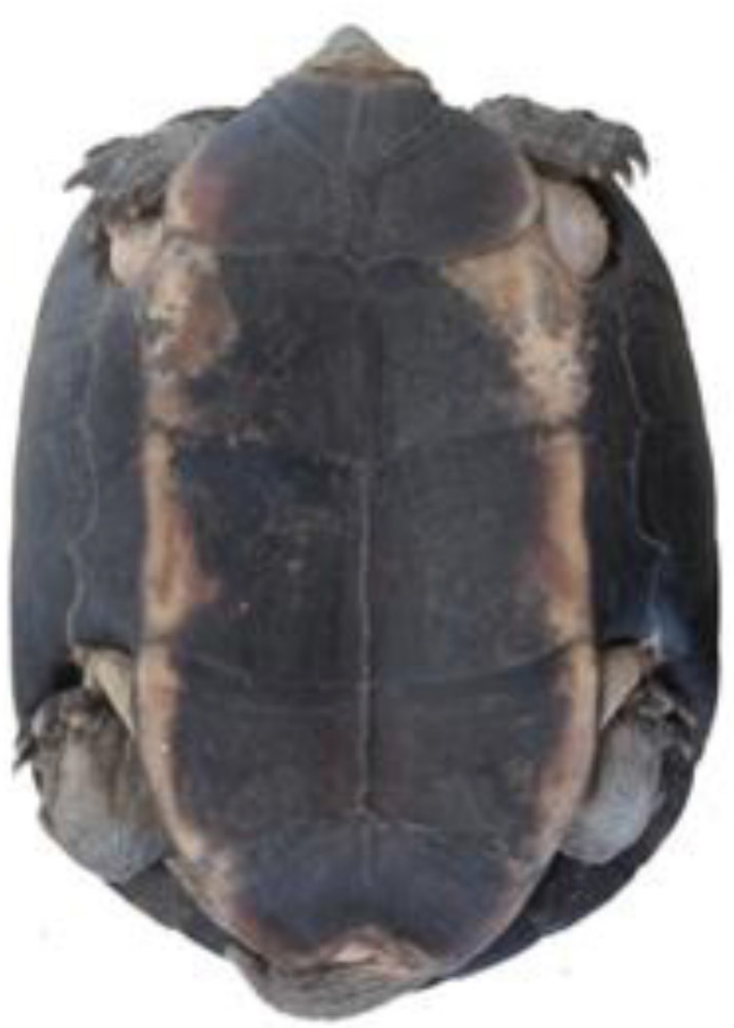

B

Figure 4. The Dorsal viewand B), Ventral viewof a Melanochelys trijuga parkeri, adult $\widehat{\partial}$ x $1 / 8$ 


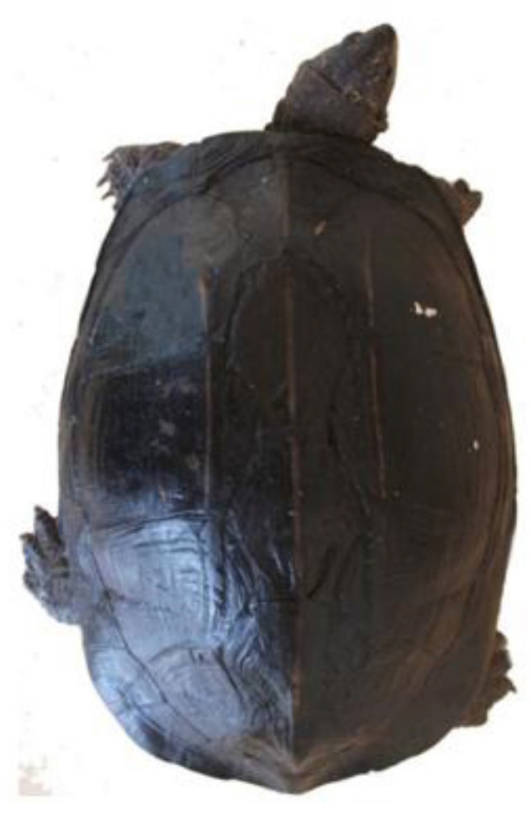

$\mathrm{C}$

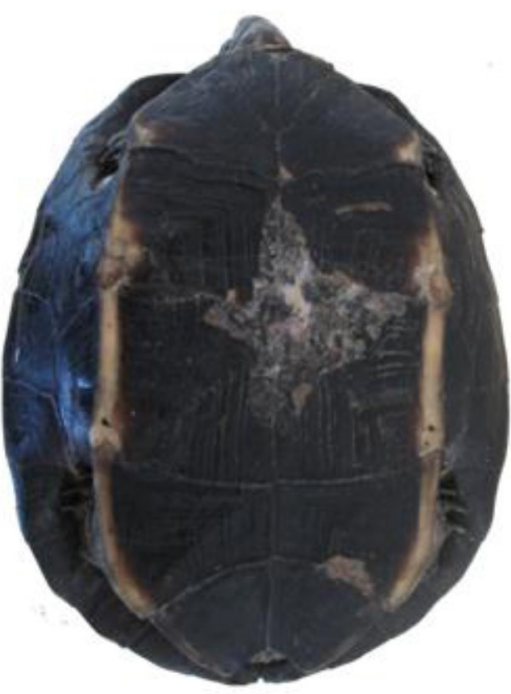

$\mathrm{D}$

Figure 5. The Dorsal viewand D), Ventral viewof a Melanochelys trijuga thermalis, adult $\hat{\delta} \mathrm{x} 1 / 8$

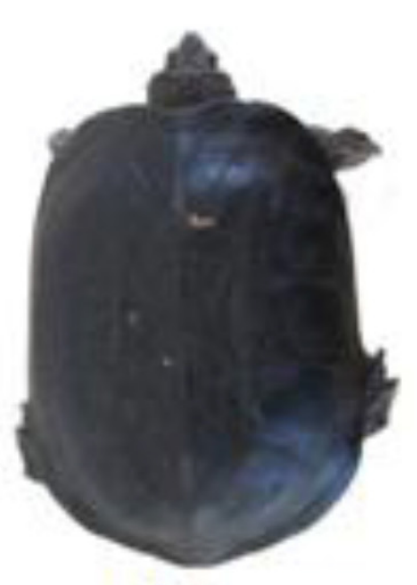

(a)
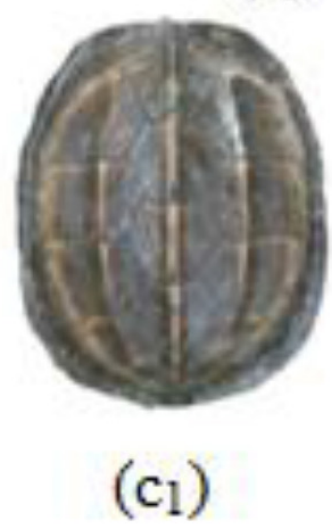

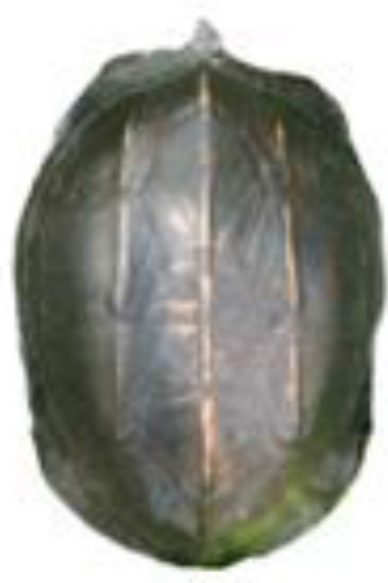

(b)

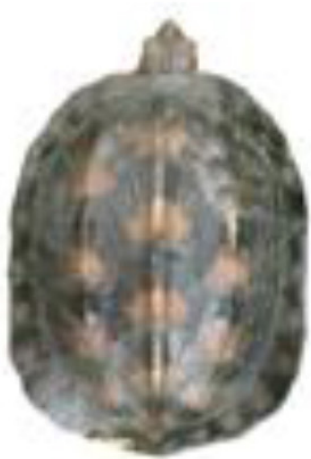

$\left(c_{2}\right)$

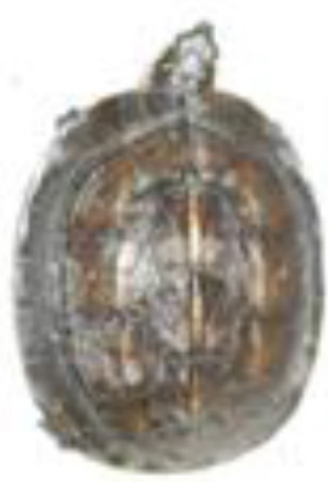

$\left(c_{3}\right)$

Figure 6. Pigmentation of the carapace of Melanochelys trijuga parkeri: a) Carapace with uniform black, b) Black with three light yellow ridges in carapace, Melanochelys trijuga thermalis: $\mathrm{c}_{1-3}$ ) Carapace with dirty brownish color and with different designs 


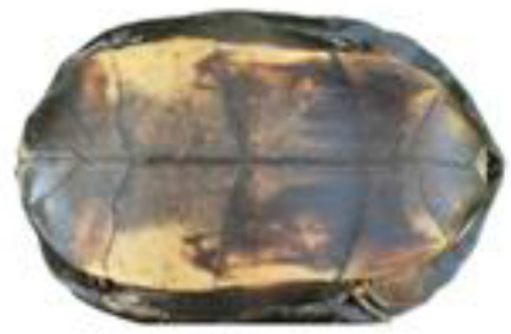

(a)

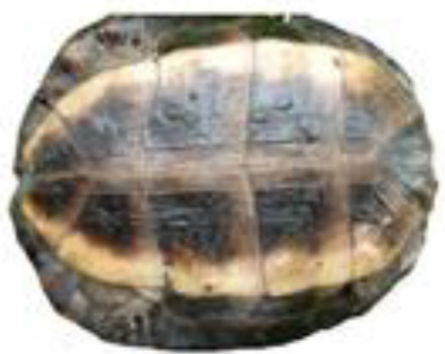

(c)

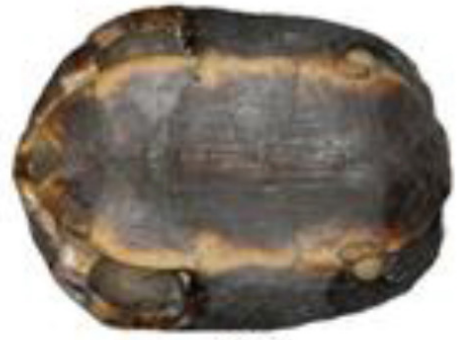

(b)

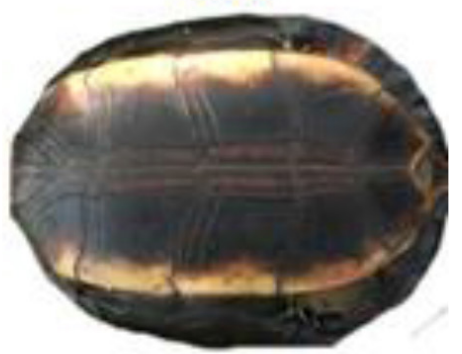

(d)

Figure 7. Pigmentation of the plastron of Melanochelys trijuga parkeri and Melanochelys trijuga thermalis: (a) and (c) is with yellow colored with a diffuse dusky central area, (b) Dark brown plastron with an orange border, (d) Plastron with yellow border.

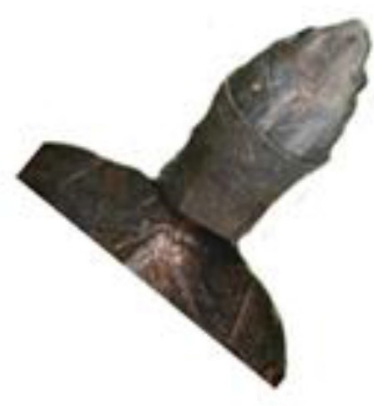

(a)

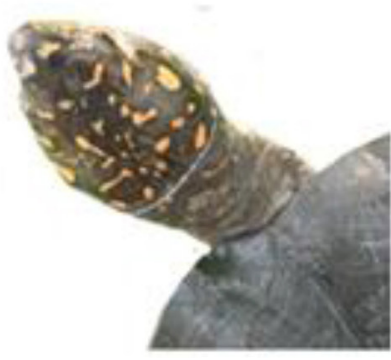

(b)

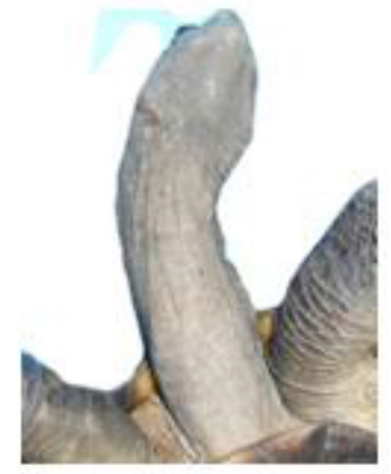

(c)

Figure 8. Appearance of upper neck region of the (a) Melanochelys trijuga parkeri and (b) Melanochelys trijuga thermalis (c) Ventral view of long neck of testudine

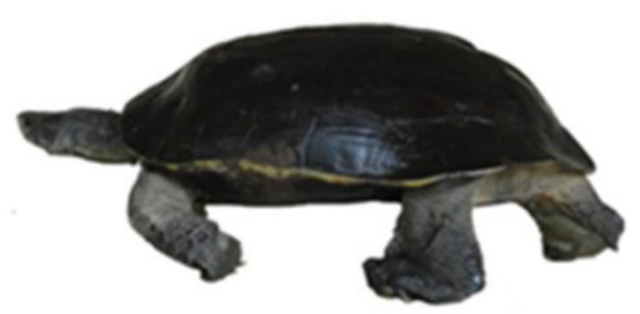

(a)

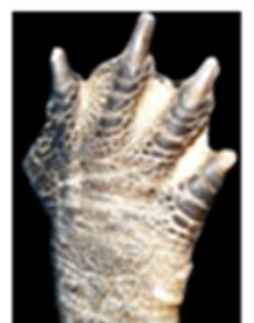

(b)

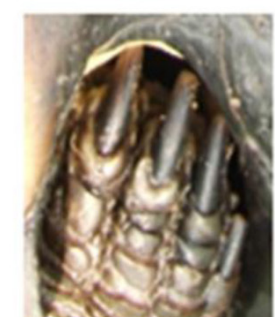

(c)

Figure 9. (a) Walking posture of a testudine, Appearance of limbs of the (b) Melanochelys trijuga parkeri and (c) Melanochelys trijuga thermalis 


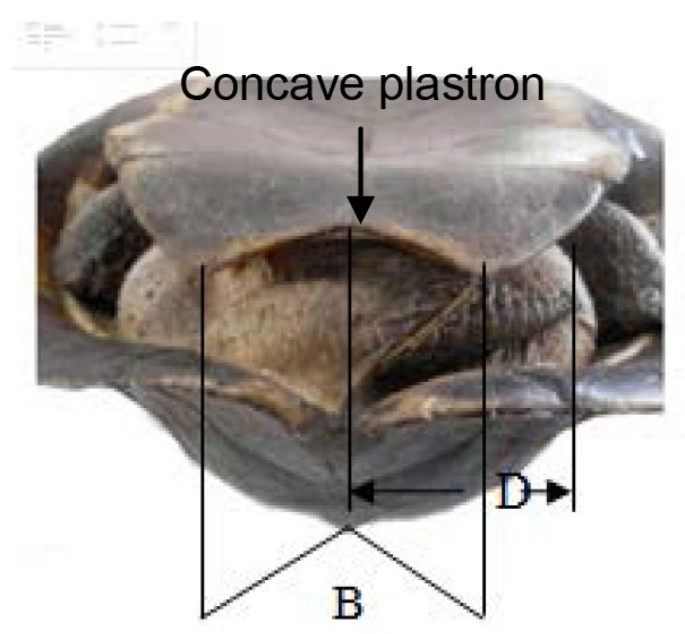

(a)

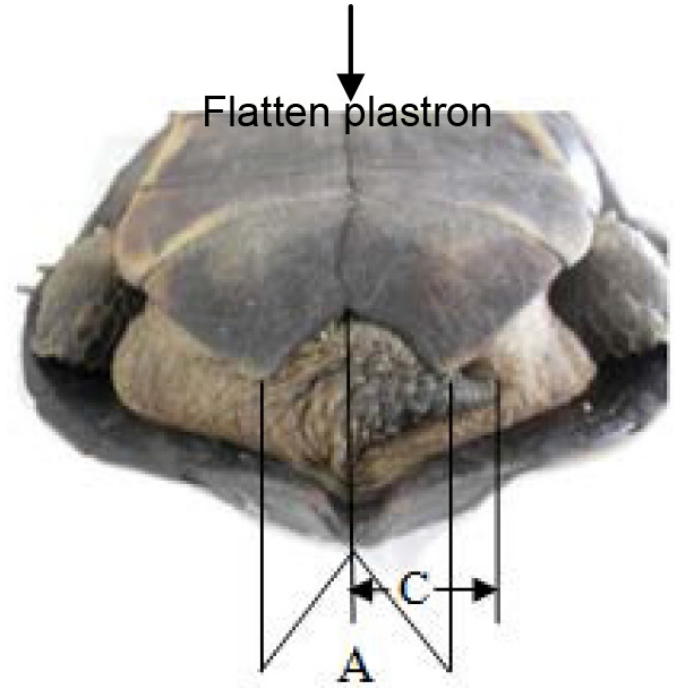

(b)

Figure 10. Caudal view of Melanochelys trijuga thermalis X 1/8, (a) Adult male (b) Adult female

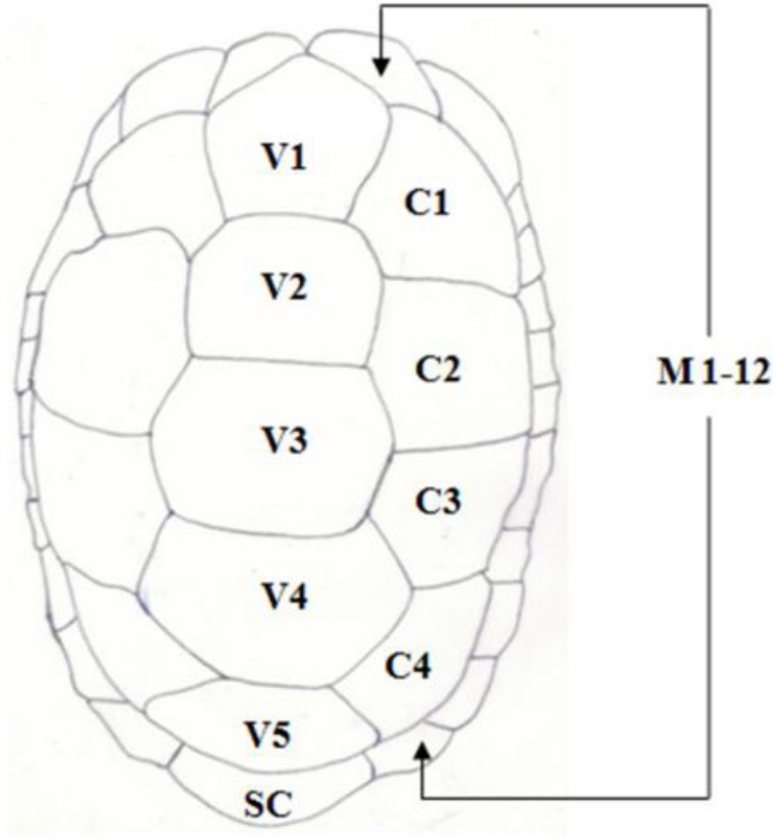

A

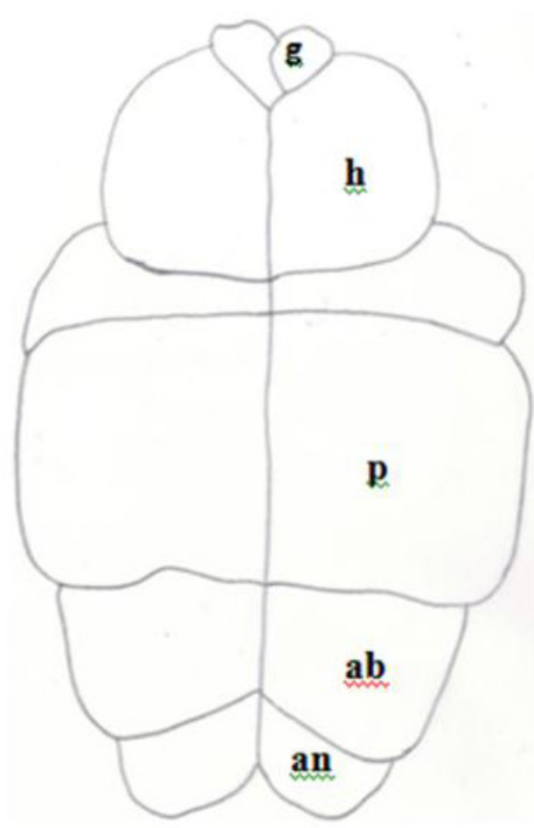

B

Figure 11. A) Pattern of scutes on carapace and plastron of Geochelone elegans: Carapace, (V) Vertibrals (1-5), (C) Costals (1-4, both sides), (M) Marginal (1-12, both sides) and (SC) Supracaudal : B) Plastron (g) gular, (h) humeral, (p) pectoral, (ab) abdominal, (f) femoral and (an) anal (all paired) 


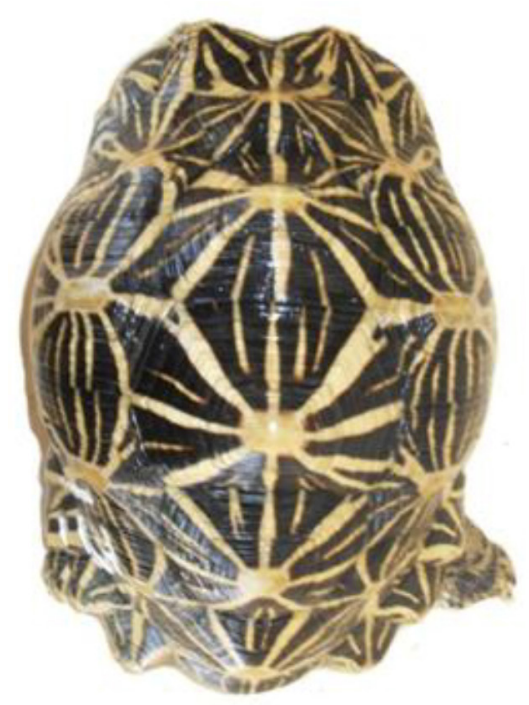

A

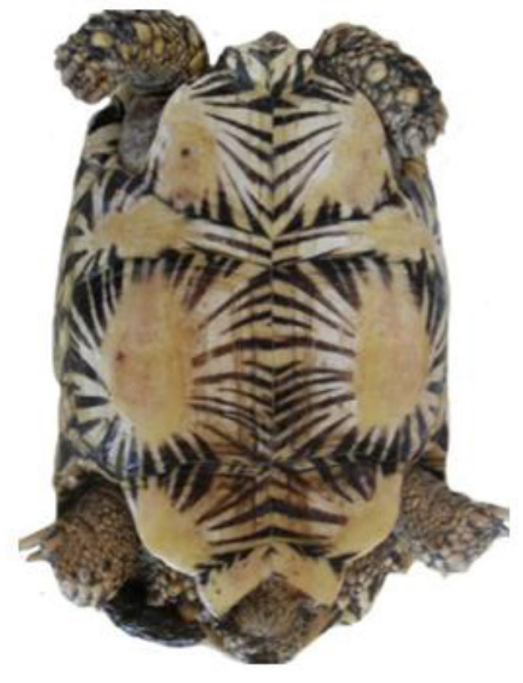

B

Figure 12. A) The dorsal view and B), the ventral view of aGeochelone elegans, adult $\delta$ x $1 / 8$
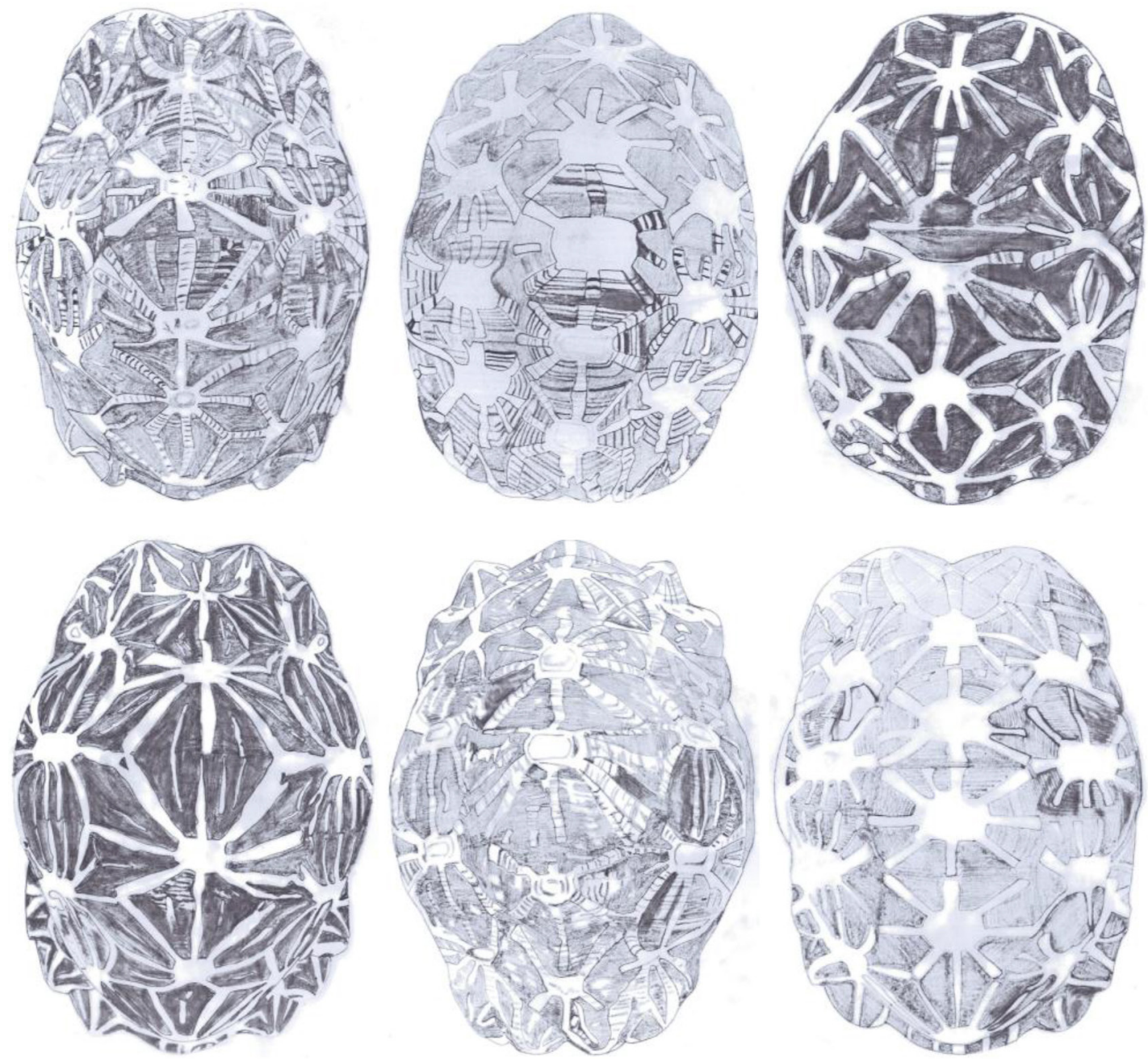

Figure 13. Carapace designs observed in Geochelone elegans, adult $\hat{\sigma} \mathrm{x} 1 / 8$ 

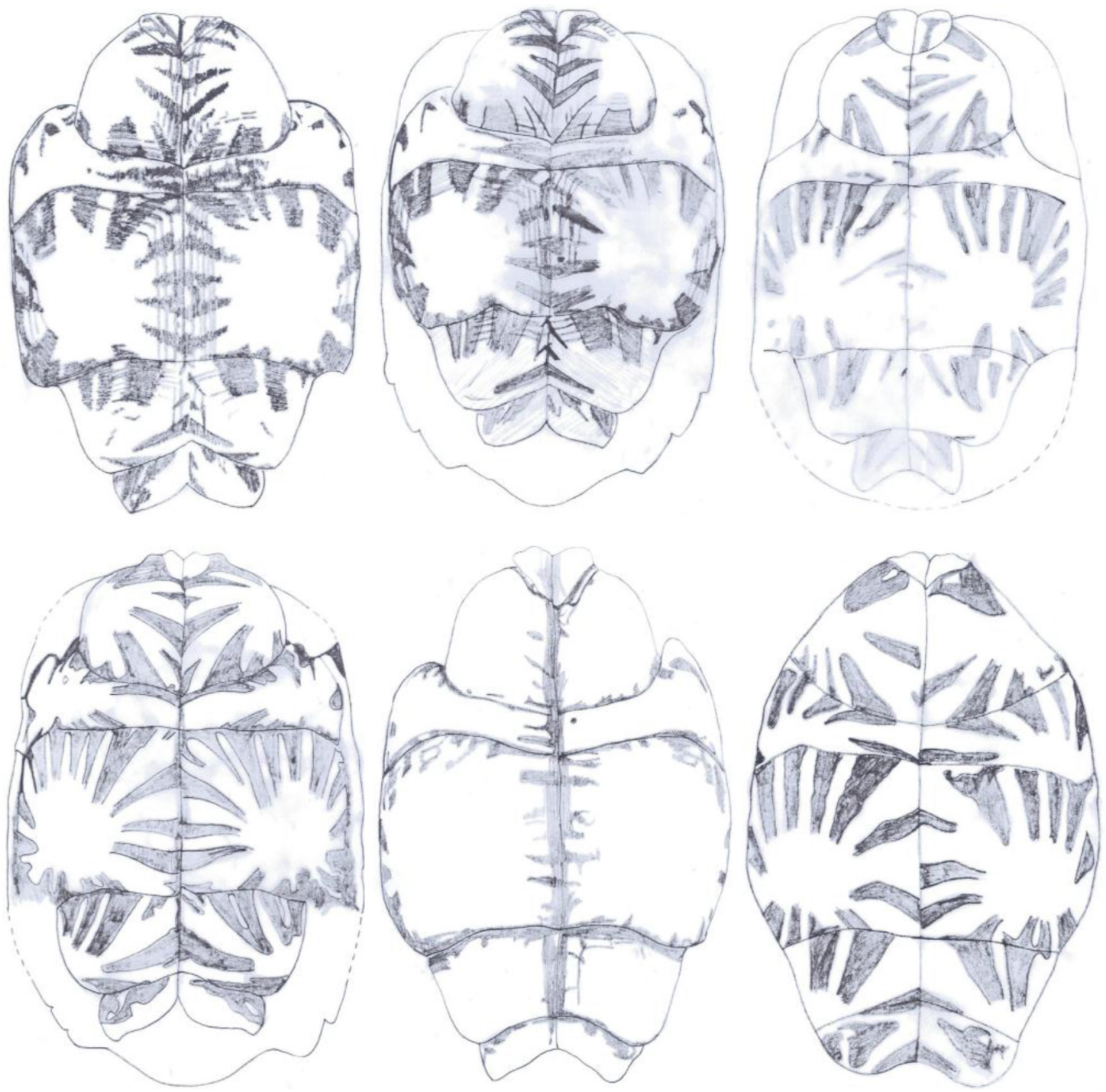

Figure 14. Plastron designs observed in Geochelone elegans, adult $\widehat{\partial} \times 1 / 8$

This soft terrapin is easily distinguished from other local testudines by its scuteless smooth skinned carapace, tubate nostrils, fleshy lips (c) and three clawed limbs with a few vestigial scales (d). The secondary sexual characters were poorly observed with our experimental group of Lissemys punctata punctate.
According to shell morphometrics observations increased body weight of was associated with increased carapace length, carapace width, carapace height, plastron length and plastron width of Melanochelys trijuga parkeri, Melanochelys trijuga thermalis, Lissemys punctata punctata and Geochelone elegans. [Figures 15-22] 


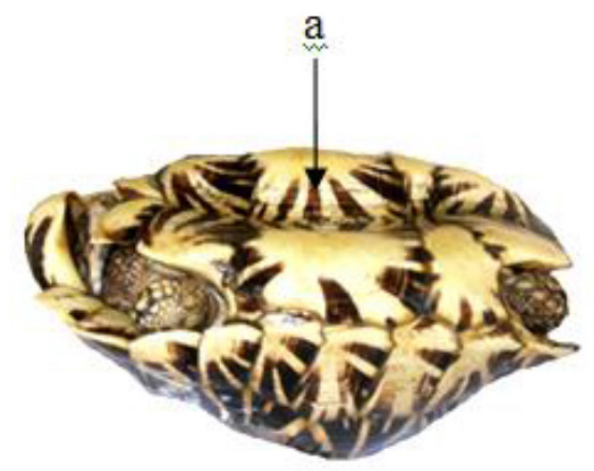

$\mathrm{A}_{1}$

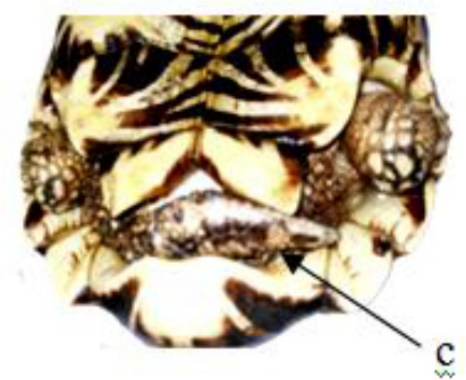

$\mathrm{A}_{2}$

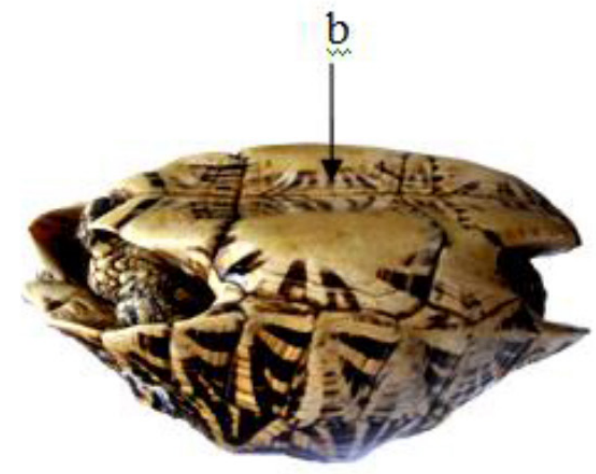

$\mathrm{B}_{1}$

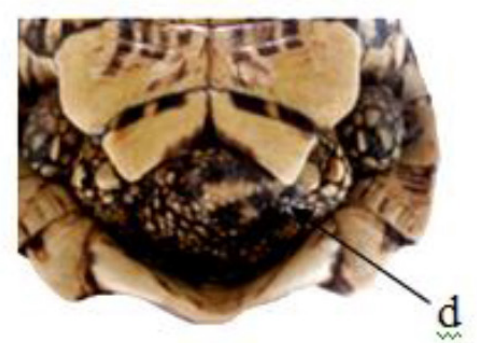

$\mathrm{B}_{2}$

Figure 15. Lateral and caudal views of Geochelone elegans X 1/8

$\left(\mathrm{A}_{1-2}\right)$ Adult male - (a) concave plastron and (c) elongated tail,

$\left(\mathrm{B}_{1-2}\right)$ Adult female - (b) flat plastron and (d) short tail

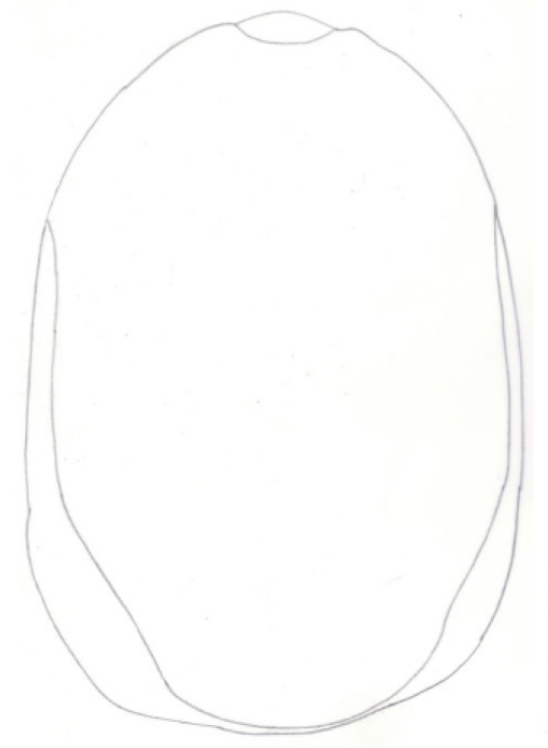

A

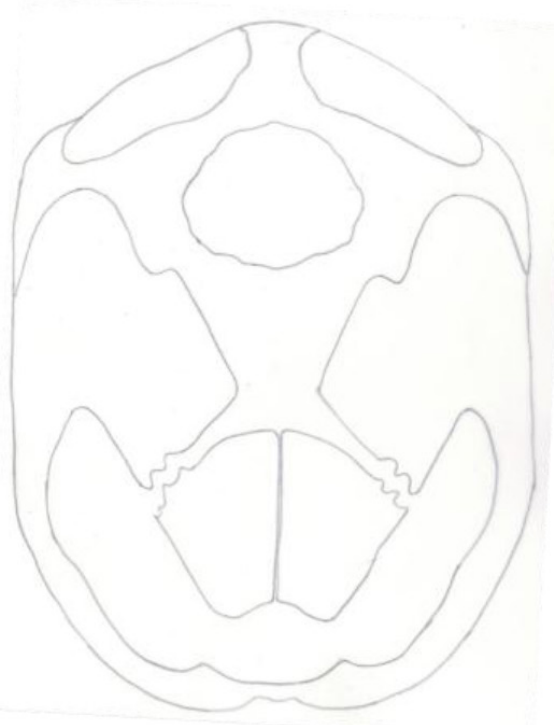

B

Figure 16. A) Plastron and B) carapace of Lissemys puntata punctata 


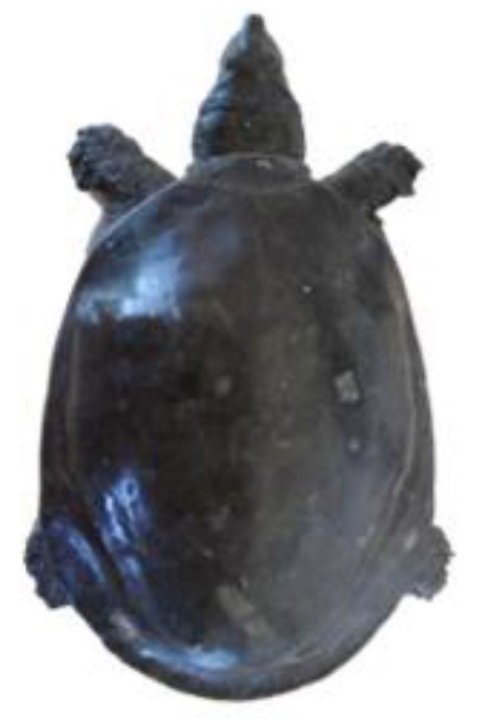

A

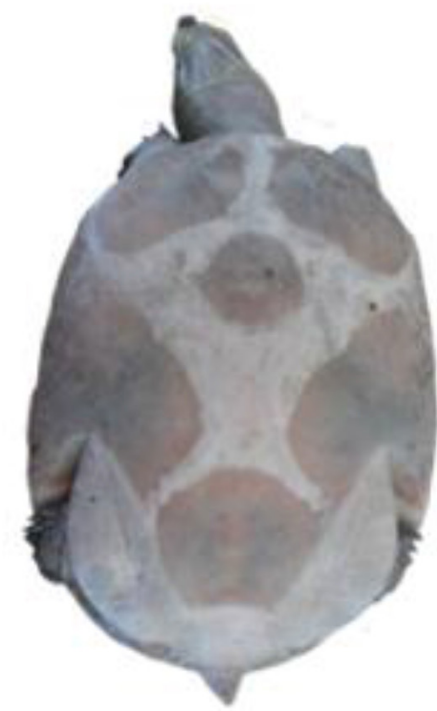

B

Figure 17. A) The dorsal view and B), the ventral view of aLissemys punctata punctata, adult $\mathrm{x} 1 / 4$

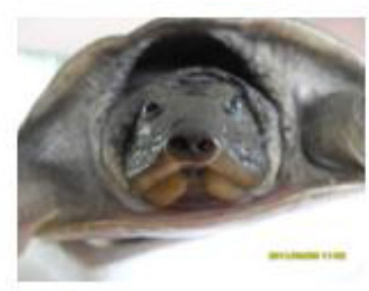

(a)

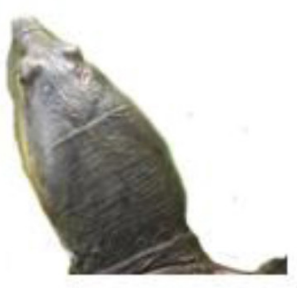

(b)

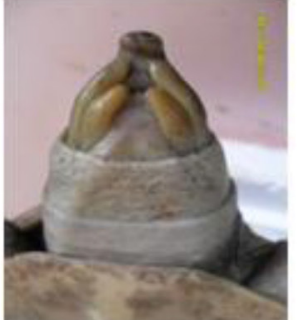

(c)

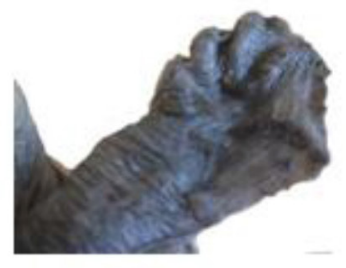

(d)

Figure 18. (a) Rostral view of head (b) Dorsal view of head, (c) fleshy lips and (d) limb of Lissemys punctata punctata

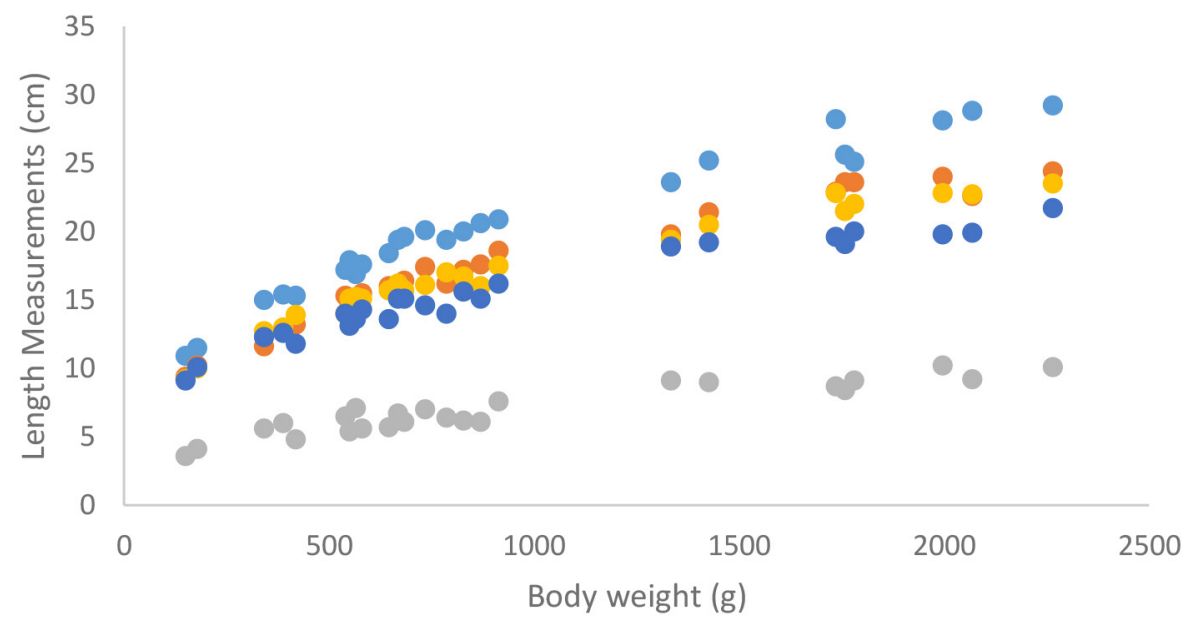

TCL OTCW OCH OTPL OTPW

Figure 19. Carapace and plastron measurements of Melanochelys trijuga parkeri

Total carapace length (TCL), Total carapace width (TCW), Carapace height (CH), Total plastron length (TPL) and Total plastron width (TPW) 


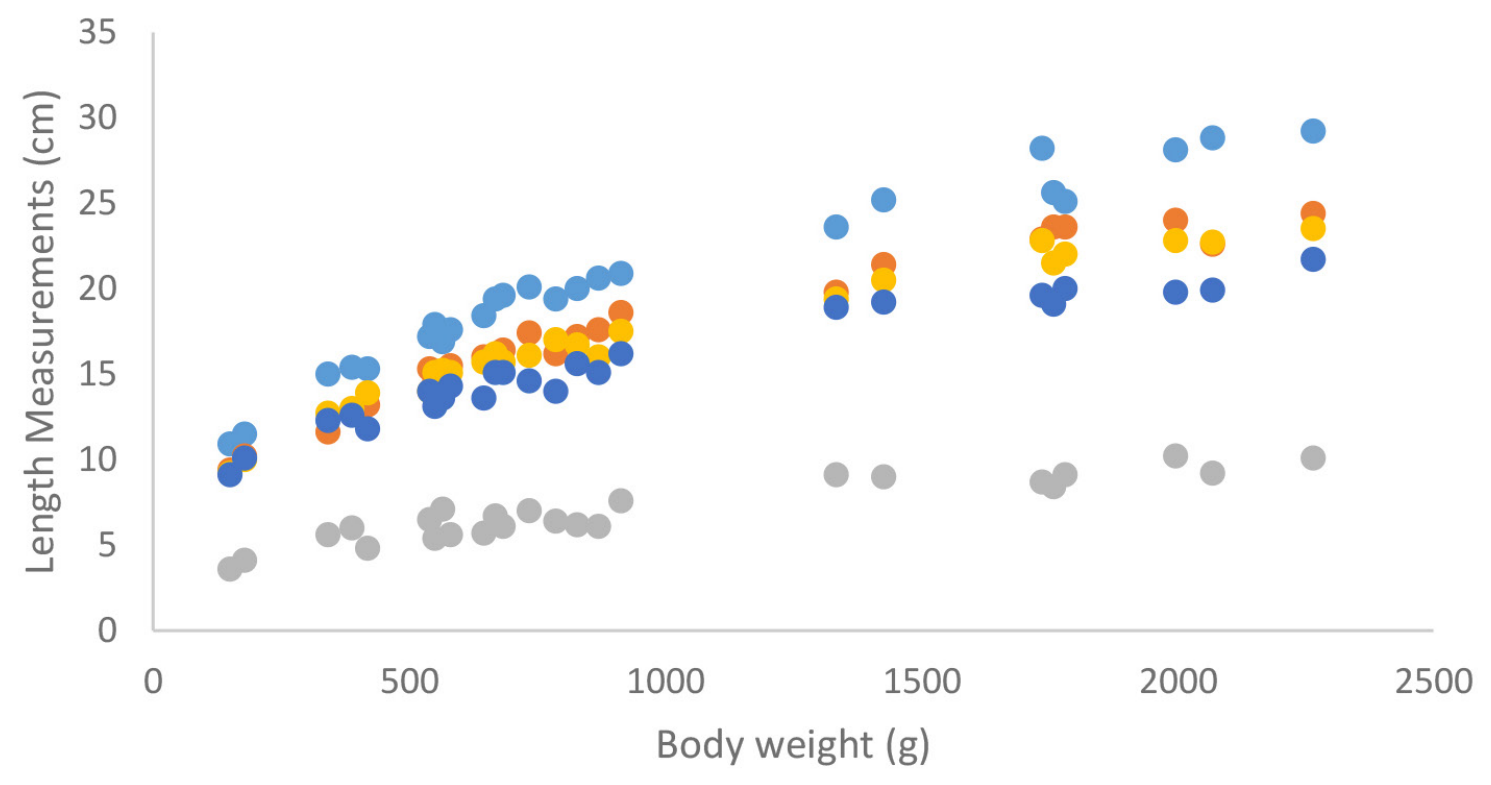

$\mathrm{TCL} \odot \mathrm{TCW} \odot \mathrm{CH} \odot \mathrm{TPL} \odot \mathrm{TPW}$

Figure 20. Carapace and plastron measurements of Melanochelys trijuga themalis

Total carapace length (TCL), Total carapace width (TCW), Carapace height (CH), Total plastron length (TPL) and Total plastron width (TPW)

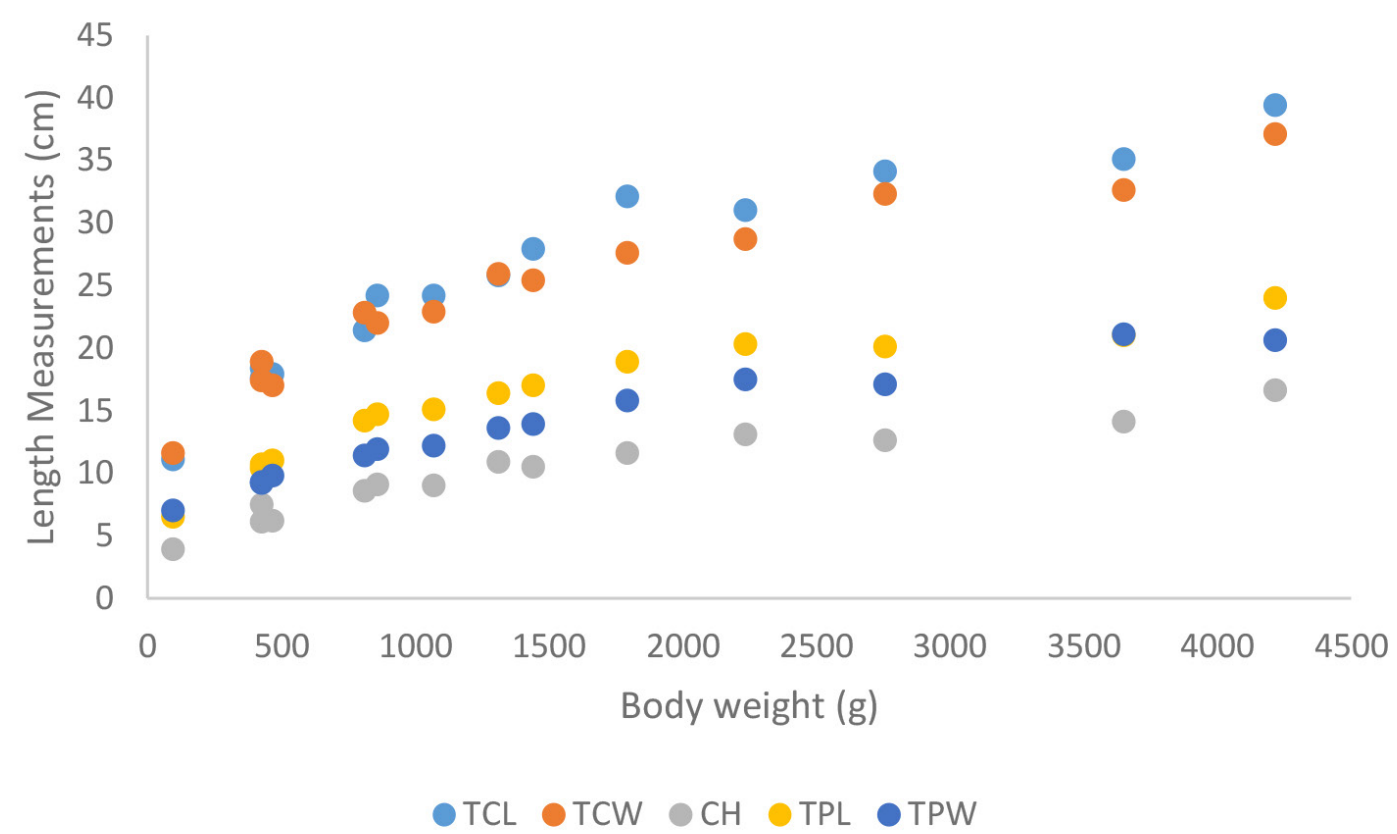

Figure 21. Carapace measurements of Geochelone elegans; Total carapace length (TCL), Total carapace width (TCW), Carapace height (CH), Total plastron length (TPL) and Total plastron width (TPW) 


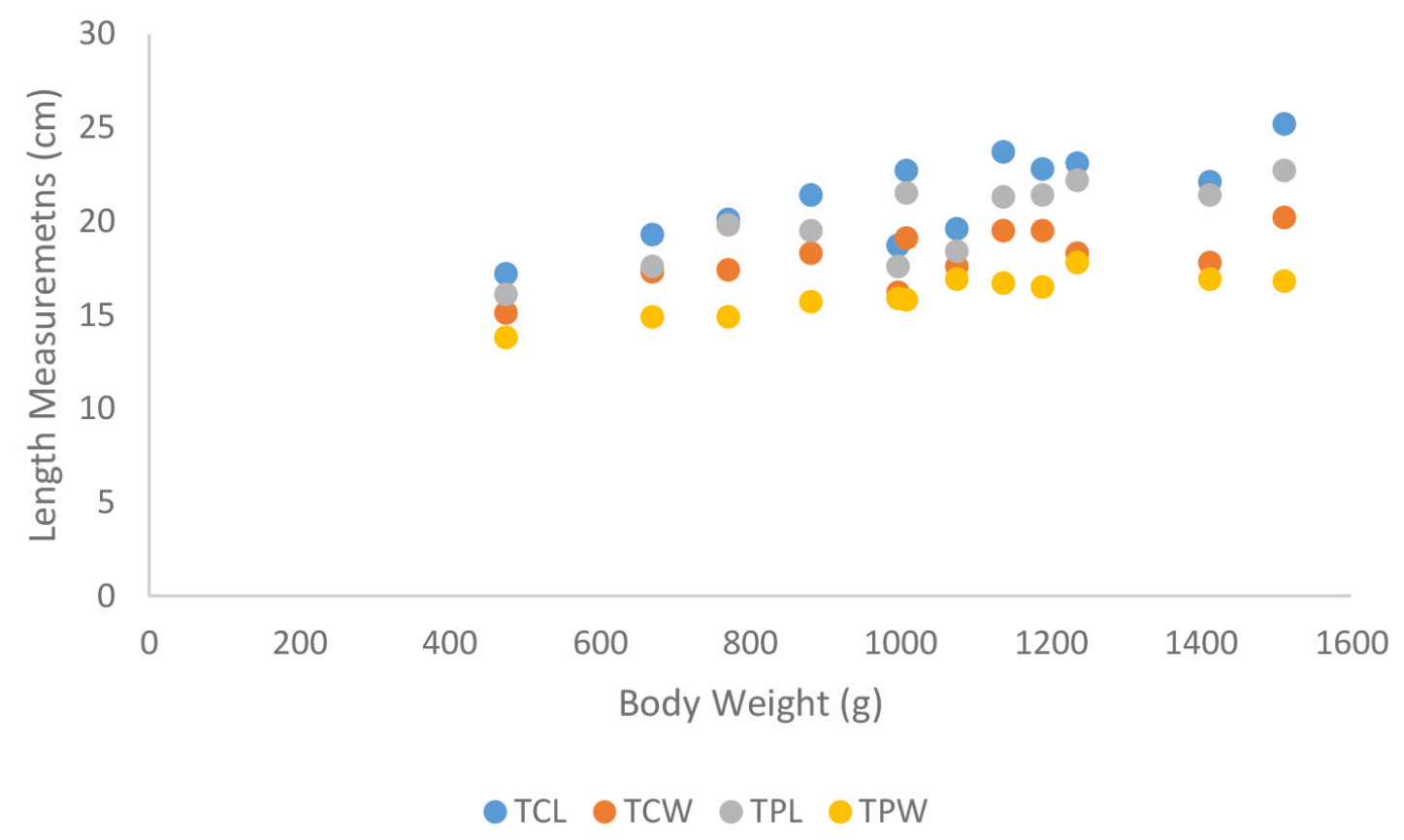

Figure 22. Carapace and plastron measurements of Lissemys punctata punctata, Total carapace length (TCL), Total carapace width (TCW), Total plastron length (TPL) and Total plastron width (TPW)

\section{Conclusion}

This article provides basic morphological information of Sri Lankan fresh water turtles and tortoises which will helpful in future research, management and conservation aspects.

\section{Acknowledgement}

The authors wish to appreciate the assistance given by the I.W.M.D.N. Sadaruwan and K. A. C. kumara, for the support given in the data collection.

\section{Conflicts of interests}

The authors would like to declare that there is no conflict of interest related to publication of this paper.

\section{Authors' Contribution}

This work was carried out in collaboration between all authors. GAP designed the study and involved in field research trials. HNND was conducted the field research trial, data collection, managed the literature searches, interpreted the data and drafted the manuscript. LJPAPJ took part in preparing and critical checking of this manuscript. GAP supported the research facilities and funding. All authors read and approved the final manuscript.

\section{References}

1. Kottawa-Arachchi JD, Wijeratne MA (2017) Climate Change Impacts on Biodiversity And Ecosystems In Sri Lanka: A Review. Nature Conservation Research 2: 2-22.

2. Marambe B, Silva P, Ranwala S, Gunawardena J, Weerakoon D, Wijesundara S, Kurukulasuriya M (2011) Invasive alien fauna in Sri Lanka: National list, impacts and regulatory framework.
3. Das I, De Silva A (2005) A photographic guide to snakes and other reptiles of Sri Lanka: New Holland.

4. Karunarathna S, Amarasinghe AT, Henkanaththegedara S, Surasinghe T, Madawala M, et al. (2017) Distribution, habitat associations and conservation implications of Sri Lankan freshwater terrapins outside the protected area network. Aquatic Conservation: Marine and Freshwater Ecosystems 27: 1301-1312.

5. Deraniyagala P (1939) The tetrapod reptiles of Ceylon.-Vol. I. Testudinates and Crocodilians. Colombo Museum Natural History Series. Colombo, Sri Lanka: Museum of Natural History.

6. DeSilva A (1996) Proposed Action Plan: Conservation, restoration and management of the Testudines and their habitats in Sri Lanka: Department of Wild Life Conservation \& Global Environmental Facility Programme.

7. Fund TC (2002) A global action plan for conservation of tortoises and freshwater turtles. Strategy and funding prospectus.

8. Hewavisenthi S (1993) Turtle hatcheries in Sri Lanka: Boon or bane. Marine Turtle Newsletter. 60: 19-21.

\section{Citation:}

Nadeesha Dilrukshi HN, Anura P Jayasooriya and Gamika A Prathapasinghe (2019) Morphological Observations on the Shell of Fresh Water Turtles and Tortoises Found in Sri Lanka. Integr J Vet Biosci Volume 3(1): 1-13. 